\title{
Editorial
}

\section{Introduction to Special Issue}

\section{Who Does or Does Not Respond to Whom or What in a Democracy? The Case of Japan}

\author{
KENTARO FUKUMOTO \\ Gakushuin University, Japan \\ Washington University in St. Louis, USA \\ Kentaro.Fukumoto@gakushuin.ac.jp
}

In a democracy, it is essential that agents respond to their principals. Because the principals have some control over the agents, the agents are supposed to be loyal to the principals' wishes. For example, in the context of an election, voters (principals) can hire and fire their representatives (agents), while lawmakers should represent their constituency and legislate accordingly. On this basis, power is delegated from principals to agents and the chain of delegation makes government work, from voters (principals) to legislators (agents), from legislators (now, principals) to ministers (agents/principals), to bureaucrats (agents/principals), and to street-level public servants (agents).

Doing what the principals say, however, does not guarantee the outcome the principals want, much less what the agents want. In some cases, agents acting independently of the principals can be better, even for the principals. A classic example is the independence of a central bank. Diligent monetary policy is necessary to maintain the value of currency, but because such policies are unpopular with the people, the executive office has an incentive to loosen monetary policy. Thus, by giving up control of the central bank (agents), the executive office (principals) can credibly commit to a diligent monetary policy on which the market can rely.

In general, principals have power but not resources (expertise, time, and so on), while agents have resources but not power. Since principals do not know, or cannot do, what is the best for principals, they delegate power to agents. For democracy to work, agents must be responsive to their principals in some cases but not in others. In addition, the principals sometimes fail to monitor the agents (agency slack), and agents do not behave as their principals want. Similarly, it is important to understand what political 
actors (do/do not) respond to, as well as to whom. Some tools (e.g., referenda, surveys) are introduced into politics to achieve a certain goal, though they do not necessarily perform in the way they are expected to; they may have side effects. It is an empirical matter whether these tools attain the intended aim. The articles in this special issue quantitatively tackle these overarching agendas from various angles, using the case of Japan.

The first two articles consider who does/does not respond to whom. Asako, Iida, Matsubayashi, and Ueda argue that resourceful dynastic politicians do not respond to voters. The authors begin by developing a game theoretic model in which politicians and voters respond to each other. Dynastic politicians are more likely to be elected (electoral advantage) and deliver larger fiscal spending (bargaining advantage). It follows that, when the dynastic candidate is too strong, the non-dynastic candidate decides not to run in the first place. As a result, the dynastic candidate is sure to be reelected and does not (have to) respond to voters any more. Consistent with this theoretical argument, the authors empirically demonstrate that districts that return resourceful, dynastic legislators enjoy larger fiscal spending from the government but, ironically, suffer from deteriorating economic conditions.

Fukumoto and Masuyama claim that the judiciary does not respond to the executive. Even though judicial independence is constitutionally prescribed, some people doubt whether the judiciary is truly independent. In particular, an OLS analysis of a seminal work shows that judges who belong to a leftist group are discriminated against for promotion. Criticizing methodological problems with this analysis, the authors reanalyzed the same data using more appropriate and robust methods: matching, survival analysis with right censoring, left truncation, and split population as well as average treatment effects on event and time. None of the results indicated that judges' promotions had anything to do with leftist group affiliation.

The remaining four articles examine who does/does not respond to what. Kim illustrates that responding to referenda increases citizens' political efficacy. The literature presumes that participation in local politics increases political efficacy, though the evidence is mixed. The author took advantage of a natural experiment. In the early 200os, some municipalities held referenda to solicit people's opinions about their municipal merger plans, while other municipalities did not. Coincidently, a panel survey repeatedly asked the same respondents about their political efficacy over the same period. Comparing within-respondent changes in political efficacy during this period for municipalities with and without referenda, the article found a positive educational effect of referenda. That is, those who lived in municipalities with referenda showed a greater increase in internal political efficacy than did those in municipalities without referenda.

Ono establishes that lawmakers respond to their own projected personal attributes. To garner personal votes, candidates often emphasize their own personal attributes in their campaigns. Once they are elected, they are expected to behave in accordance with those attributes to maintain their image. Quantitative analysis confirms this. Representatives with local political experience tend to sponsor more members' bills 
and speak more in the pork-oriented committees (but not in the non-pork-oriented committees) than do other representatives. In contrast, lawmakers with the bar are more likely to initiate more members' bills and speak more in the non-pork-oriented committees (but not in the pork-oriented committees) than do other representatives.

Kagotani maintains that people respond to foreign threats by supporting their leader, but they do not respond in the same way to international cooperation. Although few scholars doubt the 'rally-round-the-flag' effect, in which public approval ratings of national leaders jump after a foreign crisis, few can explain the phenomenon. The author discusses three mechanisms. The first is patriotism: the nation psychologically reacts to a foreign threat but not cooperation with other nations. Second, consistent with the rational demand for national defense, a foreign threat (or cooperation) makes people support (oppose) a pro-military government. Third, retrospective policy evaluations regard foreign threats (cooperation) as policy failures (successes) and predict that foreign threats (cooperation) decrease (increase) the popularity of the government. Data analysis supports the patriotism explanation.

Miwa shows that survey responses are influenced by how the questions are asked, not only by what they are asked. When survey respondents are asked to identify the positions of parties on a scale from left to right, many place parties near the center. The author suspects that there are three types of respondents. First, 'informed respondents' correctly understand the left-right scale. Second, 'middle-category inflators' do not know the answer and choose the middle category, partly because there is no 'don't know' response choice. Third, 'grade evaluators' regard the numbers on the left-right scale (the leftmost, middle, and rightmost correspond to 0,5 , and 10, respectively) as indicators of good and bad. The author develops a new statistical model, estimates it using the Markov chain Monte Carlo method, and confirms his suspicions.

This special issue attempts to shed some new light on the subtle relationship between principals and their agents in the area of Japanese politics by operationalizing variables and empirically testing hypotheses. Although the articles in this issue are diverse in their scope, they show the state of the art quantitative analysis of Japanese politics. Moreover, these articles attempt to address not only Japan-specific questions, but also universal issues. Thus, the theories provided to address these problems and the methods used to analyze the data are applicable to other countries. At the same time, we would like to demonstrate that Japan is an interesting case to make important theoretical and/or methodological contributions to the literature such as comparative politics and international relations. There remain many agendas to be studied. Hopefully, more articles on Japan written in English will answer a broader range of questions in political science.

\section{About the author}

Kentaro Fukumoto is professor of political science at Gakushuin University and visiting fellow at Washington University in St Louis. He received his Ph.D. from 
University of Tokyo. His research interests include political methodology, legislative studies, and electoral studies. He is the author of Nihon no Kokkai Seiji: Zen Seifu Rippo no Bunseki [Politics in the Japanese Diet: A Statistical Analysis of Postwar Government Legislation] (Tokyo Daigaku Shuppan Kai, 200o) and Rippo no Seido to Katei [Legislative Institutions and Process] (Bokutaku Sha, 2007). His articles have appeared in American Political Science Review, American Journal of Political Science, Legislative Studies Quarterly, Journal of American Statistical Association, and Japanese Journal of Political Science. 